\title{
InfoMax gene networks constructed from intervention in the animal models of Parkinson's disease Hesam T Dashti ${ }^{1}$, Mary Kloc*2, Tong Lee ${ }^{3}$, Gregory Michelotti ${ }^{4}$, Tingting Zhang ${ }^{5}$ and Amir Assadi ${ }^{6}$
}

\begin{abstract}
Address: ${ }^{1}$ Department of Computer Science, Tehran University, Tehran, Iran, ${ }^{2}$ Biophysics Program, University of Wisconsin-Madison, Madison, WI 53706, USA, ${ }^{3}$ Department of Psychiatry, Duke University \& Medical Center, Durham, NC 27710, USA, ${ }^{4}$ Department of Anesthesiology, Duke University \& Medical Center, Durham, NC 27710, USA, 5Department of Research Partnering, Roche Palo Alto LLC, CA 94304, USA and

${ }^{6}$ Department of Mathematics, University of Wisconsin-Madison, Madison, WI 53706, USA

Email: Mary Kloc* - kloc@wisc.edu

* Corresponding author
\end{abstract}

from Sixteenth Annual Computational Neuroscience Meeting: CNS*2007

Toronto, Canada. 7-12 July 2007

Published: 6 July 2007

BMC Neuroscience 2007, 8(Suppl 2):PI34 doi:I0.II86/I47|-2202-8-S2-PI34

() 2007 Dashti et al; licensee BioMed Central Ltd.

\section{Theoretical aspects}

This paper reports progress in construction of a new network structure, called the InfoMax Gene Network, for exploring genome-scale inter-relationships among families of genes in order to specify pathways activated during the experiments that perturb a control system. The basic mathematical theory, called Empirical Topology, provides the conceptual framework to estimate the affinity of families of genes according to their purported function in the course of perturbations. In the empirical topology approach to systems biology, the set of genes is endowed with a certain geometric structure, so that a genomic space is constructed according to representations of systemslevel information carried by the gene expression data, as 'perturbed signals' carry information regarding the noise or other factors underlying the perturbation relative to the control group. Consideration of constrained symmetries in empirical topology of the genome space provides a representation that is 'essentially unique' relative to the entropy contents of each possible signal. Application of information theory to the above-mentioned signals provides a collection of gene families in the genomic space that indicate the nodes of the InfoMax Gene Network.

\section{Experimental and biological aspects}

In our previous research we have determined the striatal mRNA expression profiles associated with dyskenesia and its reversal by the pergolide-ketanserin regimen. In experiments designed to investigate the systems biology of pergolide-ketanserin drug action, dyskinetic rats are treated subcutaneously once a day: for group $\mathrm{A}$, the rats receive pergolide followed by ketanserin; for group $\mathrm{B}$, the rats receive pergolide followed by saline; for group $\mathrm{C}$, the control group, the rats receive saline on both occasions. 6Hydroxydopamine (6-OHDA)-lesioned rats were treated with l-dopa twice a day for 21 days (days $1-21$ ) to induce abnormal involuntary movements (AIM), a model of LID. The expression levels of mRNA are recorded for 27,342 genes. The normalized values provide triplets of positive numbers $\mathrm{D}=\{(A(n), B(n), C(n)): n=1,2, \ldots 27342\}$. In this application, empirical topology on the genomic space is constructed according to the representation of the gene expression data A and B as 'perturbation of the signal' carried by the control group $\mathrm{C}$. The constrained symmetries in empirical topology of the rat genome are shown to be certain permutations of the values in the data, and suitable choices of such symmetries provide an organization of the three data sets that is 'unique' relative to the entropy contents of the signals. The InfoMax Gene Network is further constructed according to the above-mentioned the- 
ory. The biological advantage of this approach is in extracting significant functional/pathway features that are inherent in the data sets and do not require guesses or additional hypotheses that could be hard to verify under present circumstances of gene array technology. We present tables of gene families and their information-theoretic relationships, as well as the corresponding biological interpretation in the context of gene-protein networks and pathways.

\section{References}

I. Michelotti GA, Lee TH: Gene expression patterns in levodopainduced abnormal involuntary movement and its pharmacological reversal in hemiparkinsonian rats (preprint 2006, Duke University \& Medical Center). .

Publish with Bio Med Central and every scientist can read your work free of charge

"BioMed Central will be the most significant development for disseminating the results of biomedical research in our lifetime. " Sir Paul Nurse, Cancer Research UK

Your research papers will be:

- available free of charge to the entire biomedical community

- peer reviewed and published immediately upon acceptance

- cited in PubMed and archived on PubMed Central

- yours - you keep the copyright

Submit your manuscript here:

http://www.biomedcentral.com/info/publishing_adv.asp 